\title{
Design and Concept Evaluation of Tricycle for Aged and Orthopedic Differentially Abled Persons
}

\author{
Vishnuprakash $\mathrm{P}$ \\ M.E Product Design and Commerce \\ Department of Production Engineering \\ PSG College of Technology \\ Coimbatore-641004 \\ India
}

\author{
Rajesh R \\ Assistant Professor \\ Department of Production Engineering \\ PSG College of Technology \\ Coimbatore-641004 \\ India
}

\begin{abstract}
The conventional hand powered tricycle in the Indian market used by the aged and differentially abled (orthopedic) person considered for evaluation in this work. The existing conventional tricycle consumes high energy for paddling. In case of terrain climbing more energy is required for driving. So the orthopedic person gets exhausted. The current design also lacks ergonomic comfort as the crank is kept fixed and the non adjustable seat which leads to back pain and muscle fatigue. This paper aims at proposing new alternate design which overcomes all the limitations in the current design. The new design is provided with features of adjustable back rest, foot rest, and adjustable crank and related accessories. Thus the improved design meets the ergonomic issues which were lagging in the current design.
\end{abstract}

\section{Keywords}

Orthopedic, Tricycle, Backrest, Footrest, Anthropometry.

\section{INTRODUCTION}

Due to the nature, stature, age, gender, extent of disability, etc. A mobility challenged user may have different needs. A user prefers a customized design for comfortable experience. For example, the user needs the seat at preferred height with proper inclination, crank placement at certain location and provision of foot rest at required distance from the seat, back rest at specific angle.[1]

In terms of mechanical efficiency and cardio-respiratory response, arm-crank propulsion is superior to hand-rim propulsion. During all operations such as mounting, dismounting and riding including sitting, pedaling, steering and braking, the arm-crank propelled tricycle is ergonomically suitable and comfortable to the user.

The significance of suitable configuration to minimize injuries to upper extremities is given by a study performed by Faupin et al; 2008.[3] Due to many constraints, mainly considering cost as a prime factor it is practically not possible to have a custom made tricycle by every user. For this, a tricycle with adjustable features is a better solution. Extensive study on existing tricycles and wheel chairs were carried out. User's suggestions and requirements pertaining to safety and comfort were considered.

"Front Wheel drive Cycle" of Vittori; U.S Pat No. 3,848,891 issued Nov 19, 1974 is one of the developments made in tricycle design for the better usage by physically challenged peoples. The noteworthy innovation by Vittori deals only with the use of hand power and front wheel drive but the adjustable features implementation in the tricycle design was not explained. Keyserling et al; (1992) states that the trunk flexion, lateral bending and twisting increases muscular stress and vertebral disc pressure and sitting for long duration of time in the tricycle increases the risk of back pain and results in muscular fatigue. Ruby Hadley's extended mobility aims in exploring the opportunities for the people with disabilities beyond the assistive devices is currently being practiced in the production in rural areas of Uganda. [7]

\section{PRODUCT DEVELOPMENT PROCESS}

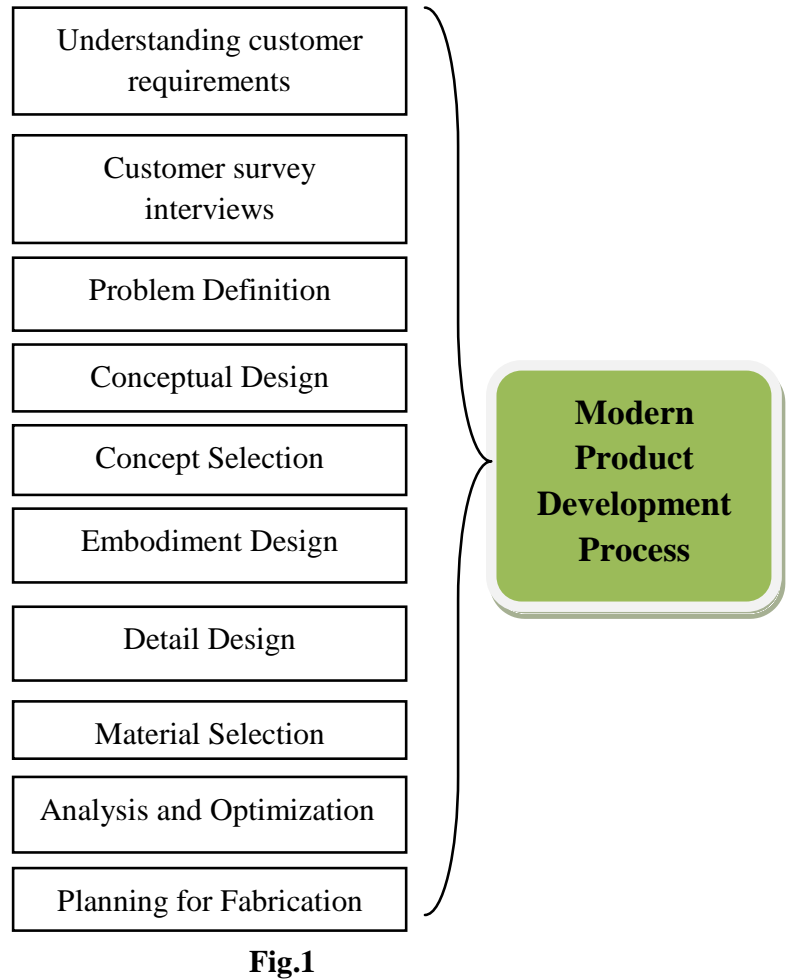

A set of inputs and outputs are transformed by a sequence of steps is called process. Physical process is one of the most familiar processes among the people. The sequence of steps or activities an enterprise employs to conceive, design and commercialize a product is called product development. The steps and activities includes intellectual and organizational apart from physical.

The precise and detailed development process is defined and followed by some organizations and others are not even able to describe their process. The classification of product development process is based on the type of technical activities performed in it. The flow chart depicts the modern product development process and sequence of activities 
performed in it. The new product development is based on understanding the customer requirements.

The existing product is analyzed for its limitations and from this the development of new design is created. For selecting the best concept and to evaluate it with many solutions conceptual designs are generated. The free hand sketching representation is considered as the ideas for concept solutions.

The Pugh chart and weighted matrix are the techniques used for selecting the best concept when the concept solutions are generated. These techniques will evaluate the concept based on the customer criteria for purchasing the product. The conceptual design stage is followed by the embodiment design stage. It deals with selection of suitable materials to the components with its dimensions. The Detail design stage lies next to the embodiment design stage consist of drawings, specifications of the components in the product. The tools used in this stage are CAD tools. Various CAD/CAE packages are used for analyzing and optimizing the design concepts.

\section{EXISTING DESIGN AND ITS EVALUATION}

In this work, the various limitations in the existing tricycles have been evaluated. In typical product development process, the product is generally evaluated based on specific set of design criteria such as cost, functionality, safety, maintenance, durability, etc., By this study, a specific set of criteria is formulated for the design of tricycle which overcomes the short comings of existing model design criteria's and its limitations. Some of the formulated criteria are concentrated in this work as follows. Ease of Transportation, Compactness, Comfort, Material used, tire size, weight and quickness to fold, etc. These criteria's further strengthened the need for a new design in tricycle. The several existing tricycle designs are shown in figure 2 to 4 . The existing tricycle limitations for the specific set of formulated design criteria are also presented in this study. One of the main disadvantages in existing tricycles is that they are found to be fixed and does not provide adjustable features to the users. According to the anthropometric data of Indians, Back rest, Foot rest, Crank position are not adjustable in the existing tricycle designs.

Thus, huge torque requirement during high terrain climbing results in early tiredness. Fixed crank and non-adjustable seat in the existing models increases back pain and muscle fatigue of the individual.

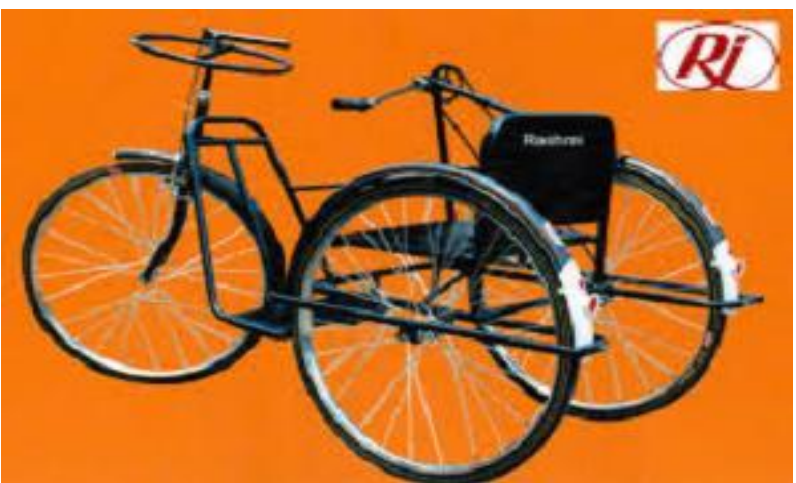

Fig. 2

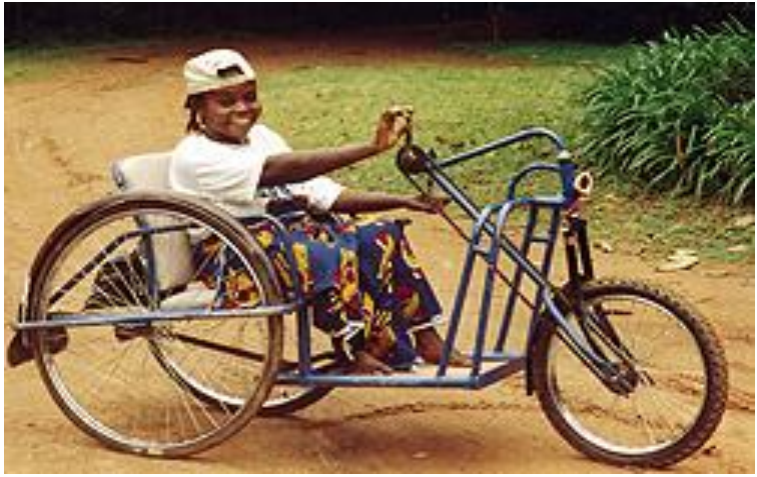

Fig. 3

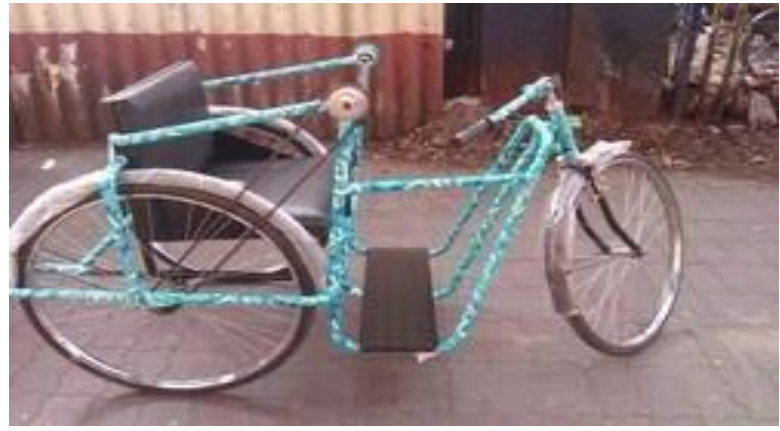

Fig. 4

In spite of having low cost in the existing tricycle, it has no ergonomics. At last there is no alternative power source except human power which causes tiredness while driving in India.

The proposed design in this study eliminates the limitations in the existing ones by enhancing the design feature besides adding some additional features.

\section{GENERATION OF SUB FUNCTIONS:}

Here, various sub functions that are needed to accomplish the overall function are identified and generated. The function tree diagram is usually used to identify the sub functions. Concepts are generated by different ways by using each sub function.

In the current study the following sub functions are identified based on the functional diagram. They are 1. Frame shape 2 . Frame Type, 3. Drive mechanism, 4. Front wheel/Rear wheel, 5.Crank, 6. Drive, 7. Joints, 8.Seat Design, 9. Fork and Steering, 10. Frame Design. To accomplish of the overall function of the product the sub function identified is utilized.

\section{GENERATION OF METHODS TO ACCOMPLISH THE SUB FUNCTIONS}

The next stage in product design is to develop as many concepts as possible for each sub function. To accomplish each sub function a variety of options would be available. The available options for each sub function are then identified as real devices or sub components. These sub components which represent the sub functions are arranged in a logical manner to accomplish the main overall function. In the current study the subcomponents needed for the formulated sub functions like frame shape, drive mechanism, seat design etc. have been determined. The table shows the number of sub components needed for the corresponding sub functions. 


\section{CONSTRUCTION OF MORPHOLOGICAL MATRIX}

A Morphological Chart is a representation of variety of subcomponents to achieve each sub function. It contains several rows and columns and resembles like a matrix. Each row contains a particular sub function and different methods by which it can be accomplished. [4]

On completion of Morphological Chart, a variety of possible sub components that could be used to achieve a particular product sub function can be arrived. Further, any sub component under a particular sub function can be combined with other sub components in other rows of the matrix in various combinations to result in a wide range of product configurations to accomplish the overall function of the product.

Table 1 shows the morphological Chart containing several sub components possibly contributing to the particular sub function. For example in the table shown, to accomplish the sub function "joining" the various sub components may be used in the design procedure are fasteners, welds and rivets. The five different Conceptual design for the effective tricycle manufacturing have been proposed using the given Morphological Chart by combining each sub component under particular sub function with several other sub components under different sub functions such as frame shape, frame structure, links, drive mechanism, etc in order to achieve overall function.[2]

Table.1 Morphological Chart

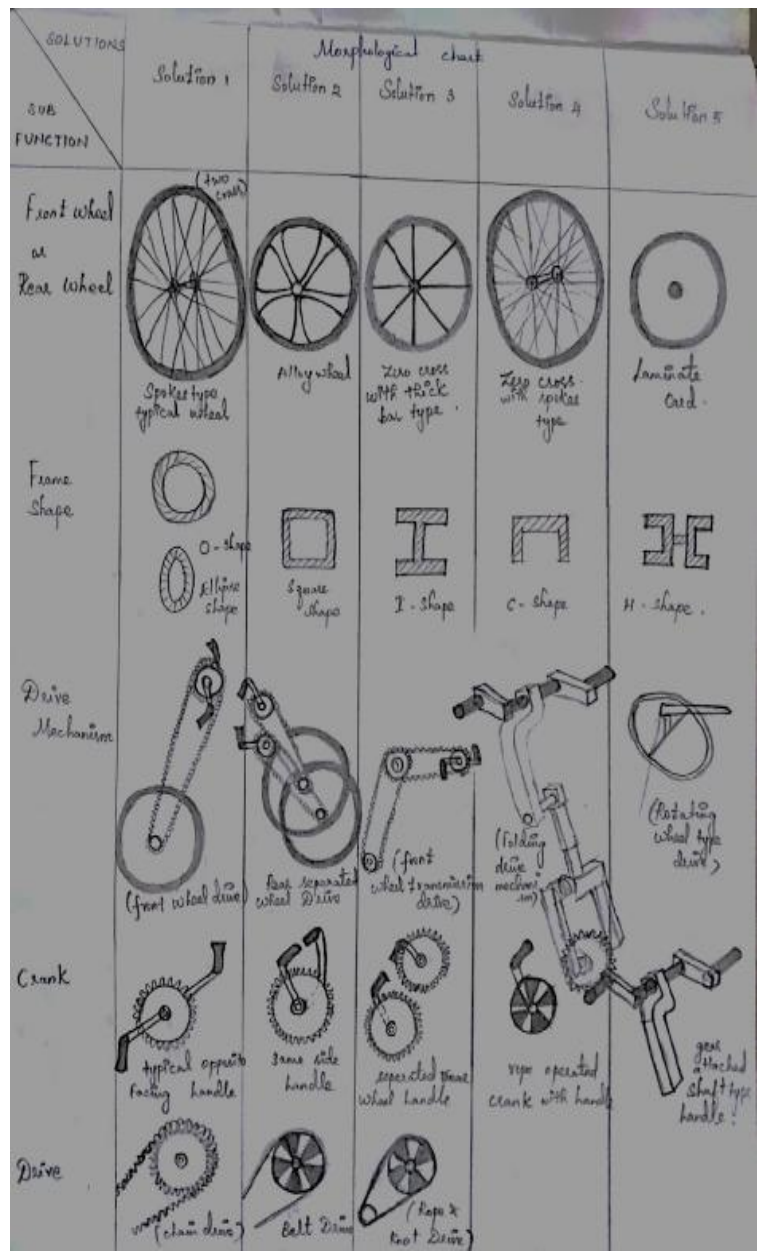

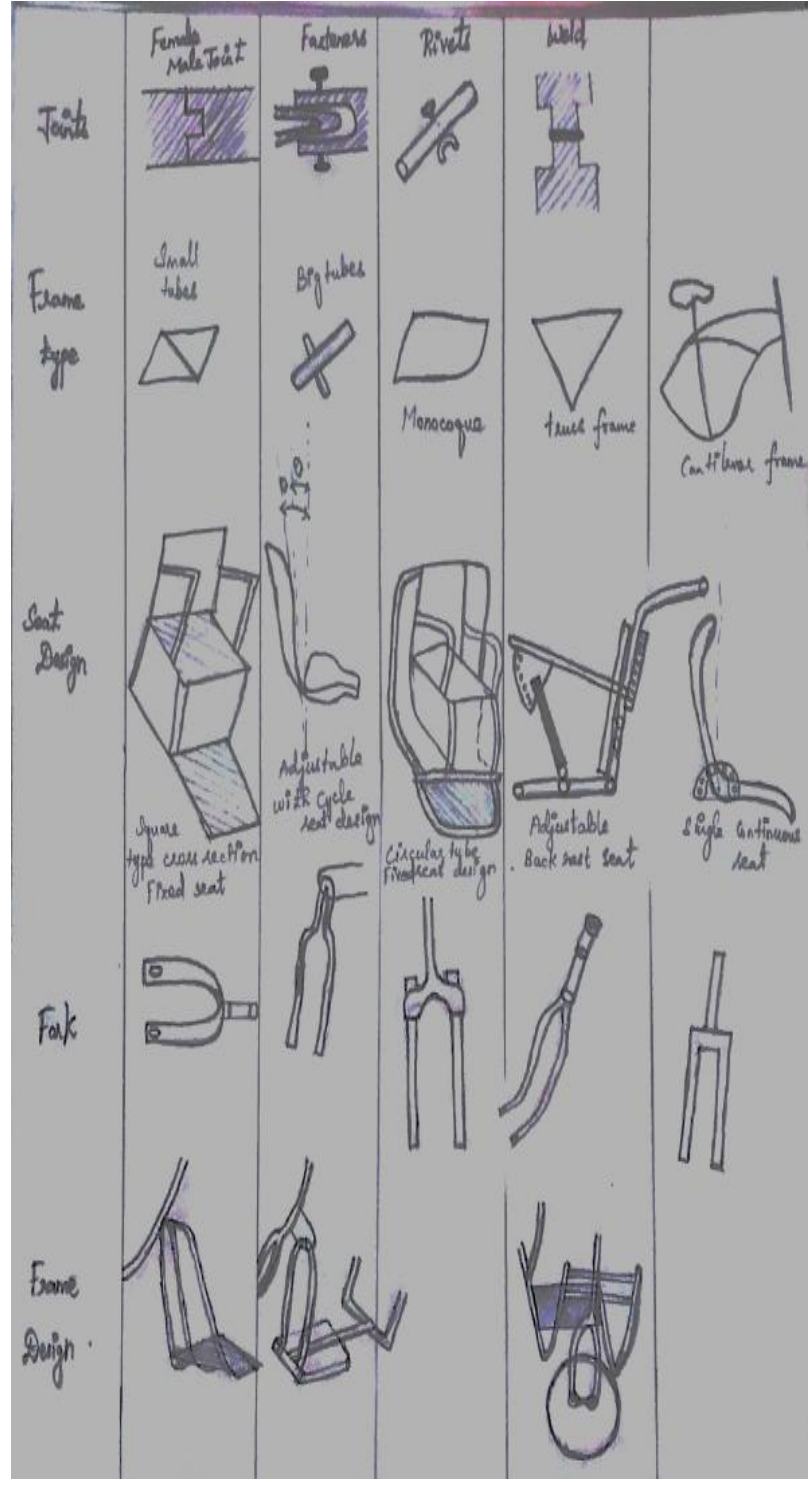

\section{CONCEPT GENERATION THROUGH} SKETCHING

The product concepts are generated by using pencil drawing as free hand sketches in the conceptual design stage. Free hand sketches are flexible than CAD diagrams which is too rigid. The initial free hand sketches tell the possible numerous solution concepts for the identified problem. [5]

In the conceptual design stage, paper and pencil work are used whereas in case of detail design such as modeling of parts and FEA CAD applications are used. During the conceptual design stage, the need for the flexibility of speed is accomplished by paper work.

The effective methods such as drawing and free hand sketching are used to develop an idea or thought to solve a definite problem and to design the ideas of the product that are to be expressed. In case of conceptual design stage, drawing and free hand sketching are the symbolic language for the designer. In General, the sketches start as a valuable idea or a solution to a problem and it is continuously enhanced by adding some minute details to improve the features of design by successive iteration. 


\section{COMBINATION MATRIX FOR CONCEPTUAL SKETCH}

Table.2

\begin{tabular}{|c|l|}
\hline \multicolumn{1}{|c|}{ Concept } & $\begin{array}{l}\text { Combination matrix for } \\
\text { conceptual sketch }\end{array}$ \\
\hline Concept sketch $\mathbf{1}$ & $\begin{array}{l}(1,1)+(2,1)+(3,1)+(4,1)+(5,1)+ \\
(6,4+(7,1)+(8,3)+(9,5)+(10,4)\end{array}$ \\
\hline Concept sketch $\mathbf{2}$ & $\begin{array}{l}(1,1)+(2,2)+(3,3)+(4,1)+(5,1)+ \\
(6,4)+(7,1)+(8,1)+(9,4)+(10,2)\end{array}$ \\
\hline Concept sketch 3 & $\begin{array}{l}(1,1)+(2,1)+(3,5)+(4,1)+(5,1)+ \\
(6,4)+(7,1)+(8,3)+(9,4)+(10,1)\end{array}$ \\
\hline Concept sketch 4 & $\begin{array}{l}(1,1)+(2,1)+(3,2)+(4,3)+(5,1)+ \\
(6,1)+(7,1)+(8,1)+(9,4)+(10,1)\end{array}$ \\
\hline Concept sketch 5 & $\begin{array}{l}(1,1)+(2,1)+(3,1)+(4,1)+(5,1)+ \\
(6,4)+(7,1)+(8,5)+(9,4)+(10,4)\end{array}$ \\
\hline
\end{tabular}

In this study, based on the combinations generated from Table.1, five designs have been proposed in this section.

Concept sketches play an important role in product design and development process. The initial sketches that are drawn may sometimes be used as a tool to generate new ideas. The sketching in the product development process acts as a bridge between an idea as a thought and a physical representative of the idea as an object. The free hand sketches give the flexibility in producing concepts and facilitate easy manipulation of the concepts, and they don't have any geometrical and topological constrains etc.

In this study, as many solutions as possible to a given design problem have been generated by means of sketching. Generally the cad packages slow the ease and speed with which sketches can be created. The concept sketches provide quicker communication and retrieval at an early stage of design.

The above Table. 2 represents the conceptual sketch 1 evolved from combination:-

$(1,1)+(2,1)+(3,1)+(4,1)+(5,1)+(6,4)+(7,1)+(8,3)+$ $(9,5)+(10,4)$. It has to be noted that the combination matrix represents only the sub components chosen under a sub function and which may not necessarily be in the logical order or sequence in which each sub component is connected to the other.

Conceptual sketch 1 shows a typical Indian tricycle, which doesn't have an adjustable features but it is less cost when comparing to other tricycles.

Conceptual sketch 2 proposes a tricycle, which has a simplified structure.

It has been generated from the combination:-

$(1,1)+(2,2)+(3,3)+(4,1)+(5,1)+(6,4)+(7,1)+(8,1)+$ $(9,4)+(10,2)$ It also follows the same principle as concept 1 with slight change in drive type.

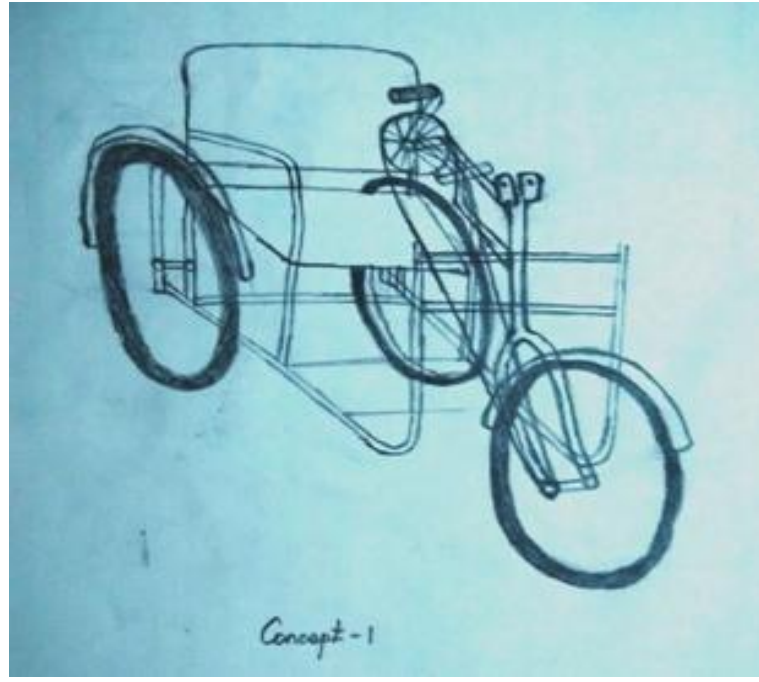

Fig.5 Concept-1

The proposed tricycle shown in Conceptual sketch 3 has a rotary wheel steering and has side rotating crank. The design has been developed from the combination:-

$(1,1)+(2,1)+(3,5)+(4,1)+(5,1)+(6,4)+(7,1)+(8,3)+$ $(9,4)+(10,1)$.

It has less human comfort for orthopedic personalities due to its drive mechanism.

Conceptual sketch 4 proposes a design which has double side crank for tricycle to move and it does not give much comfort to the users. The design has been conceived by the combination:-

$(1,1)+(2,1)+(3,2)+(4,3)+(5,1)+(6,1)+(7,1)+(8,1)+$ $(9,4)+(10,1)$

Conceptual sketch 5 is new model has adjustable features in terms of backrest, footrest, angular and linear adjustment of frame and crank according to the anthropometry datas of users. For seat design it has lock and pin mechanism for changing the angularity of backrest in order to give comfort when they get tired and fatigue during travelling.

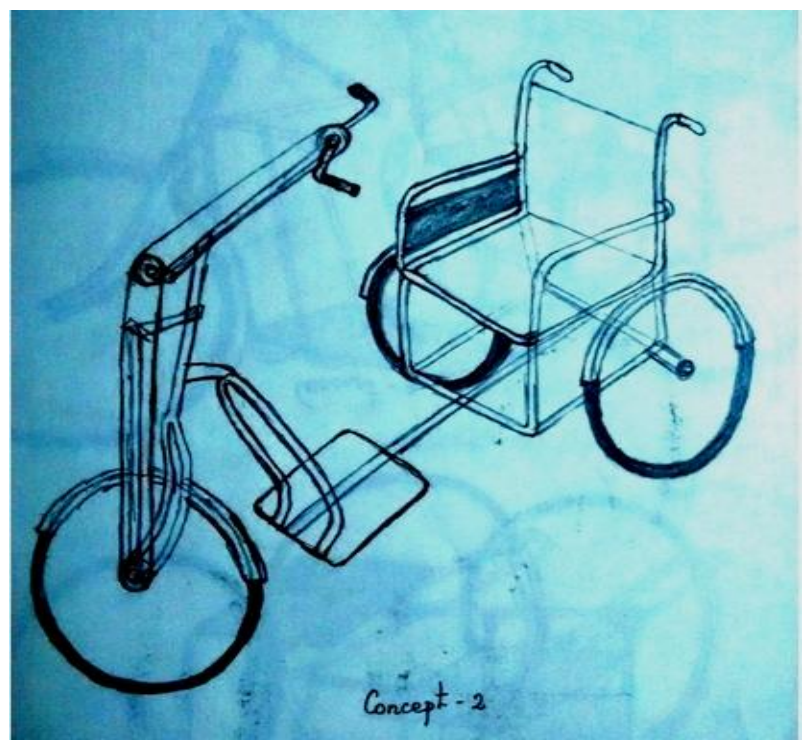

Fig.6 Concept-2 


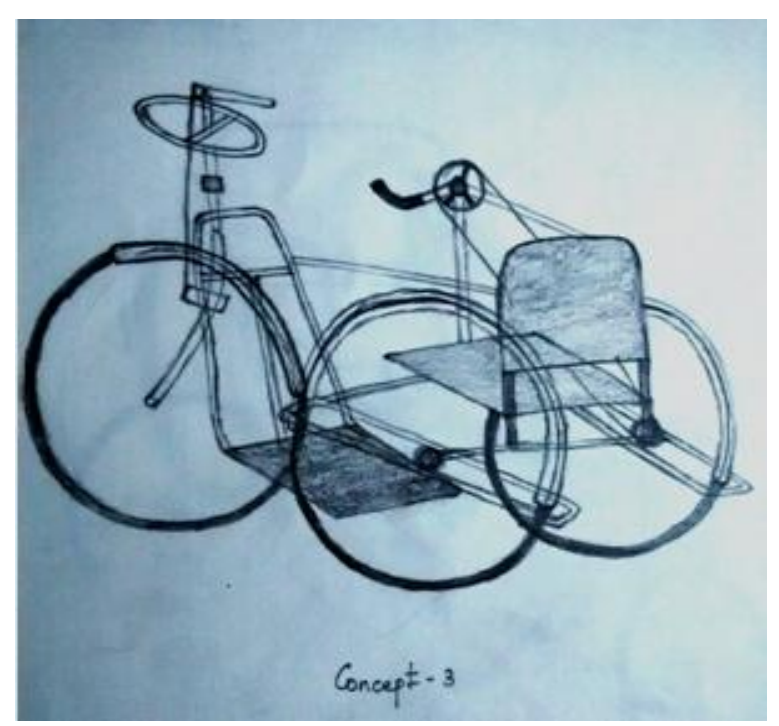

Fig.7 Concept-3

It also has telescopic mechanism for footrest which is easy to change angular and linear adjustments according to our footrest. It has another adjustments provided for linear and angular adjustments of crank position according to the users position.

The proposed design in concept sketch 5 has been obtained from combination:-

$(1,2)+(2,1)+(3,1)+(4,1)+(5,1)+(6,4)+(7,1)+(8,5)+$ $(9,4)+(10,4)$.

The proposed concepts in this study may offer some advantages like ease of adjustability, simple design, less cost etc. A lot of designs could be generated further by effective use of morphological chart by combining various sub components in it.

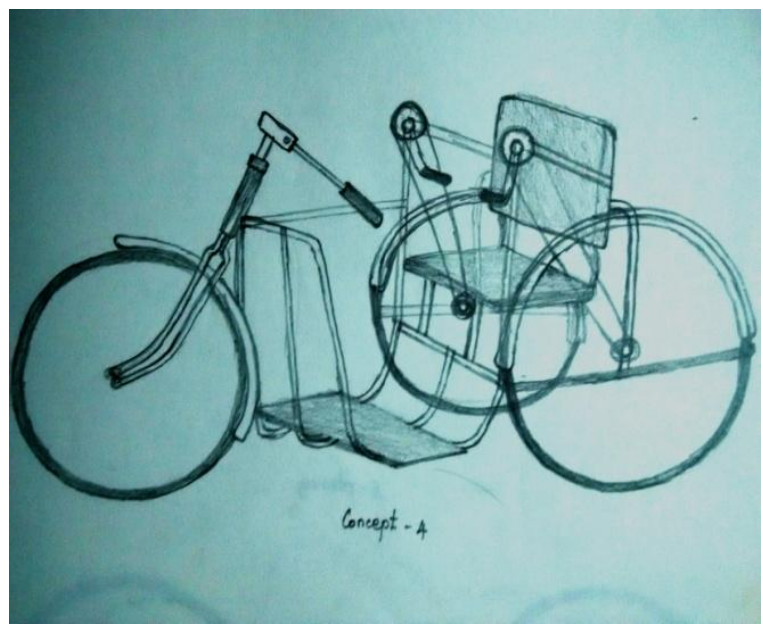

Fig.8 Concept-4

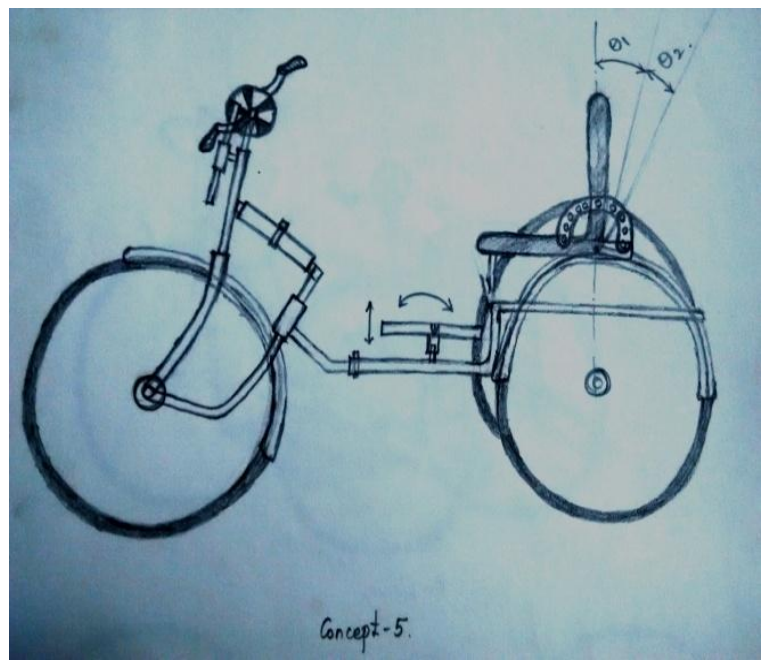

Fig.9 Concept-5

Table.3

\begin{tabular}{|c|c|c|c|c|c|c|}
\hline \multirow[t]{2}{*}{ Pugh Concept Selection Chart } & \multirow[t]{2}{*}{ Datum } & concept & concept & concept & concept & concept \\
\hline & & 1 & 2 & 3 & 4 & 5 \\
\hline Criteria 1 : Easy of Maintainability & 0 & + & + & + & + & + \\
\hline Criteria 2 : Affordable cost & 0 & - & - & - & - & + \\
\hline Criteria 3 : Ease of manufacturing & 0 & + & - & - & - & + \\
\hline Criteria 4 : Easy to use & 0 & + & 0 & 0 & + & + \\
\hline Criteria $5:$ Joints and links & 0 & - & - & - & - & - \\
\hline Criteria 6 : Easy of fold ability & 0 & - & - & - & - & - \\
\hline Criteria 7 : Good portability & 0 & + & - & - & - & $\begin{array}{l}+ \\
+\end{array}$ \\
\hline
\end{tabular}




\begin{tabular}{|c|c|c|c|c|c|c|}
\hline Criteria 8 : Good Ergonomics & 0 & + & - & + & + & + \\
\hline Criteria 9 : Easy of Adjustability & 0 & - & - & - & - & + \\
\hline Criteria 10 : Good Speed & 0 & + & + & - & - & + \\
\hline Criteria 11 : Good Aesthetics & 0 & + & + & - & - & + \\
\hline S- & & -4 & -7 & -8 & -8 & -2 \\
\hline $\mathrm{S}+$ & & +7 & +3 & +2 & +3 & +9 \\
\hline $\mathrm{S}$ & & +3 & -4 & -6 & -5 & +7 \\
\hline
\end{tabular}

Table.4

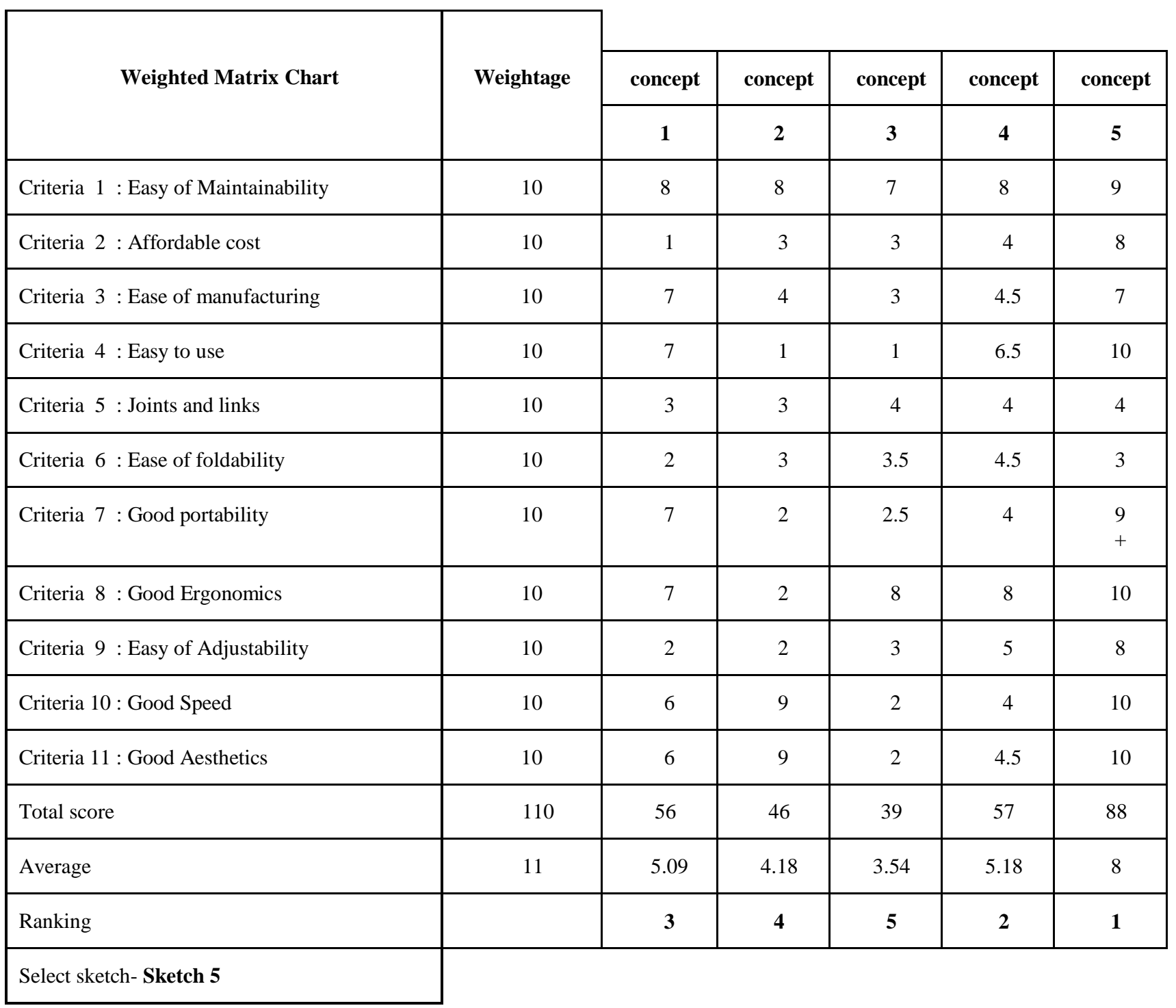




\section{DRIVE MECHANISM}

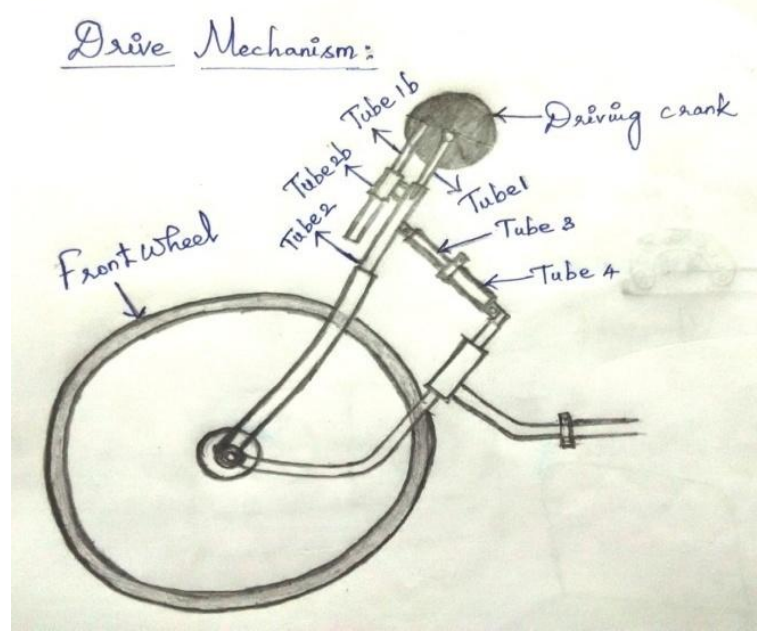

Fig.10

\section{BACK REST MECHANISM}

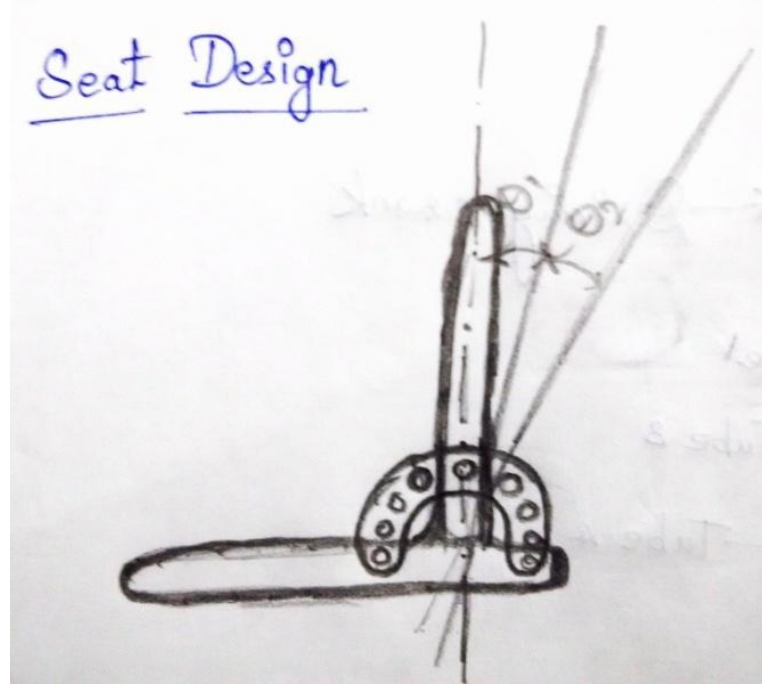

Fig.11

\section{FOOT REST MECHANISM}

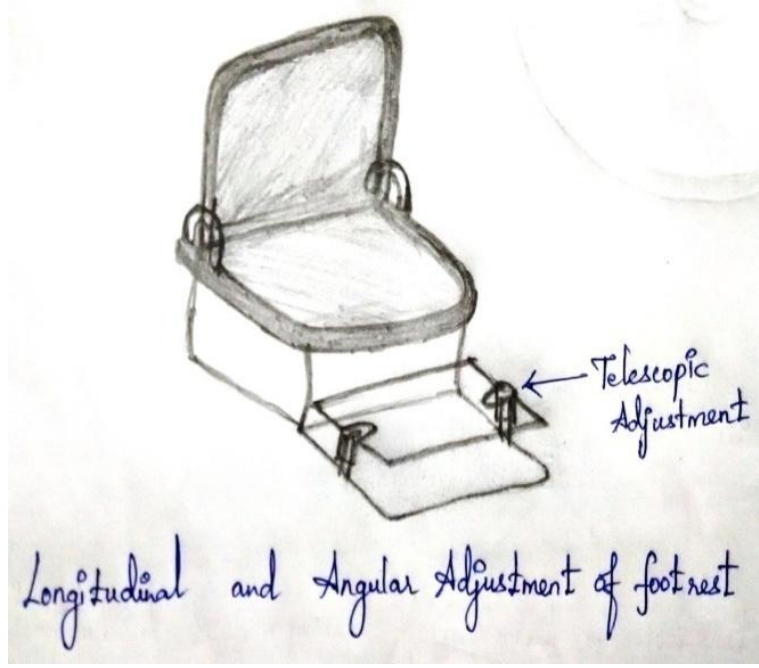

Fig.12

\section{DESIGN CALCULATIONS}

The design project allows us to get a fundamental understanding of how materials and the mechanics of those materials are used in real world situations, with real world application. We were required to design a tricycle that can safely withstand $150 \mathrm{~kg}$ and an acceleration of $4.6 \mathrm{~m} / \mathrm{s}^{2}$. This design was done first, on the individual parts to ensure that each portion of the tricycle was capable of supporting the stresses induced by the forces and reactions acting on them. After making educated assumptions, analysis was performed on the individual parts, and finally on the total design for the final testing. The Tricycle performed as expected from the assumptions and calculations. [6]

Before we begin our analysis of various components, it first necessary to find the required force applied on the pedal, such that the tricycle will accelerate at a rate of $4.6 \mathrm{~m} / \mathrm{s}^{2}$. To do this first the inertial force is found by,

$$
\begin{aligned}
I_{m} & =m a=W a / g=(1470 * 4.6) / 9.81 \\
& =689.2966 N=690 N(\text { approx })
\end{aligned}
$$

Since this is the resisting force of the motion of the tricycle, this is also the force resisting the motion of the gear, or the tension in the chain.

Now the required force applied on the pedal is found (summation)

$M_{c}=0=F L_{c}-T R$
$F=T R / L_{c}=(689.2966 * 89) / 178=344.3 \mathrm{~N}$

Therefore, $\mathrm{F}=345 \mathrm{~N}$.

\subsection{Tricycle Chain:}

The tensile force in the chain, which is equal to inertial force of the tricycle, was found to be

\section{$T=690 \mathrm{~N}$}

Since the links contain holes in the stress in the link is not distributed evenly, but reaches a maximum near the hole. The maximum stress acting on the outer links in the chain is found by

$$
\sigma_{\text {max }}=K \sigma_{\text {nom }}=K(F / A)
$$

Where $\mathrm{K}$, the stress-concentration factor, was found to be 2.4

$\sigma_{\max }=2.4(690 /(2 * 1.5875 * 6.35))=82.137 \mathrm{~N} / \mathrm{mm}^{2}$

The shear stress acting on the pin holding the links together is given by,

$$
\begin{aligned}
\tau & =F / A=T / 2 \pi r^{2} \\
& =\left(690 / 2 * \pi * 1.5875^{2}\right)=43.6 \mathrm{~N} / \mathrm{mm}^{2}
\end{aligned}
$$

\subsection{Pedal/Crank Assembly}

To analyze the maximum state of stress acting on the crank, we choose a point on the surface of the crank, for maximum shear stress, and a point at the furthest distance away from the pedal, for maximum bending moment stress.

Since the stresses acting on the crank are a combination of the torsion and bending moment, the total state of stress is given by,

$$
\begin{aligned}
\sigma_{x} & =0 \\
\sigma_{y} & =M / S=\left(F L_{c} / \pi d^{3} / 32\right) \\
& =(345 * 178 * 32) /\left(\pi * 12.7^{3}\right)=305 \mathrm{~N} / \mathrm{mm}^{2}
\end{aligned}
$$


$\tau=T_{r} / I_{p}=16 F L_{p} / \pi d^{3}$

$$
=(16 * 345 * 102) /\left(\pi * 12.7^{3}\right)=88 \mathrm{~N} / \mathrm{mm}^{2}
$$

With the state of stress found at this point on the crank, the principle stresses and maximum shear stress are calculated as shown below.

$$
\begin{aligned}
\sigma_{1,2} & =\left(\sigma_{x}+\sigma_{y}\right) / 2 \pm\left[\left(\sigma_{x}-\sigma_{y} / 2\right)^{2}+\tau_{x y}{ }^{2}\right]^{1 / 2} \\
\sigma_{1,2} & =(305 / 2) \pm\left[(0-350 / 2)^{2}+88^{2}\right]^{1 / 2} \\
\sigma_{1} & =328.57 \mathrm{~N} / \mathrm{mm}^{2} \\
\sigma_{2} & =-23.5 \mathrm{~N} / \mathrm{mm}^{2} \\
\tau_{\text {max }} & =\left(\sigma_{1}-\sigma_{2}\right) / 2 \\
& =(328.57+23.5) / 2=176.035 \mathrm{~N} / \mathrm{mm}^{2}
\end{aligned}
$$

\section{CONCLUSION}

In this study, adjustable tricycle design has been proposed after evaluating the existing tricycles in Indian market. By evaluating the existing designs, the limitations in the designs were found out which paved ways for exploring new adjustable tricycle designs which overcome all those limitations. The sub functions which contribute to the overall product function are generated from functional diagram. To accomplish the different sub functions, possible sub components are identified and a morphological chart was generated. From the morphological chart, sub components under each product sub functions are combined to develop six new concept designs. The new designs thus developed have been represented using free hand concept sketching.

Thus the existing tricycles in the Indian market are evaluated to find out the best concept by using the concept selection methods like Pugh chart and weighted matrix as shown in
Table $3 \& 4$. The selected concept will be used for embodiment design where the materials and dimensions are fixed followed by analysis and optimization.

\subsection{Future Work}

With the avail of above conceptual design procedure, the prototype can be prosperously developed in the future Provision of motor to drive the hand crank to reduce fatigue engendered to the individuals during terrain climbing will integrate extra benefit to the above developed design.

\section{REFERENCES}

[1] Aditya Soni, Ramanathan Muthuganapathy, Sandipan Bandyopadhyay, "Adjustable Hand-cranked Tricycle for Mobility Disabled".

[2] Arunachalam M., Arun Prakash R. and Rajesh R., "FOLDABLE BICYCLE: EVALUATION OF EXISTING DESIGN AND NOVEL DESIGN PROPOSALS",

[3] A.Faupin, P.Gorce, "The effects of crank adjustments on handcycle propulsion", International Journal of Industrial Ergonomics 38,577-583,2008.

[4] Kevin Otto and Kristin wood, Product design techniques in reverse engineering and new product development, Pearson education, south Asia, 2012.

[5] Karl T.Ulrich and Steven D.Eppinger, Third Edition, Tata McGraw-Hill Publishing Company Limited.

[6] David Lopez, Jovan Mayfield, \& Pierre Marc Paras, "Stress Analysis of a Bicycle", Polytechnic Institute of New York University.

[7] Ruby Hadley, Carmen Liu, Andrew Theobald, Alyssa Wongkee, "HARAMBEE PROJECT", Design Innovation for Disability. 